\title{
革命根据地经济建设创新精神融入《纲要》课程教学研究
}

Research on the Innovative Spirit of Economic Construction in the Revolutionary Base Area and the

\section{Teaching Research of Outline}

魏俊

Jun Wei

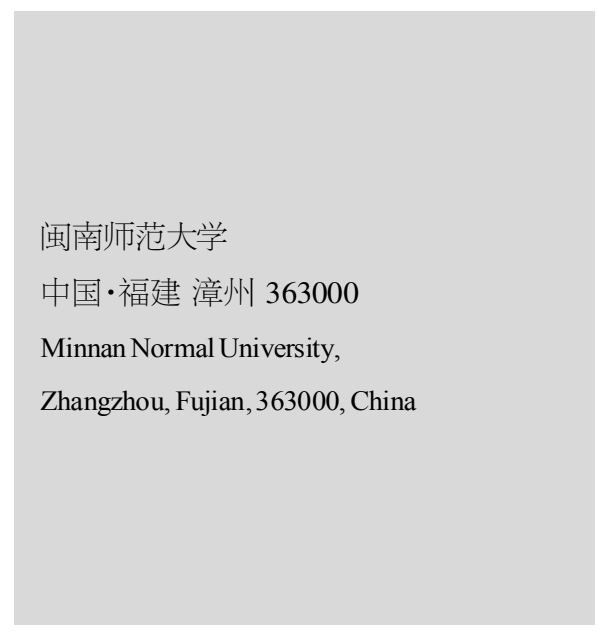

【摘 要】将革命根据地经济建设创新精神融入《纲要》课程教学研究是拓宽《纲要》课程教学 课上的教学内容, 以具有创新性创造性的经济类史料来吸引大学生的学习兴趣,使当代大学生 深刻领会革命根据地经济建设的深层次的精神, 培养学生创新和科学精神。

【Abstract】Integrating the innovative spirit of economic construction in revolutionary base areas into the teaching research of Outline curriculum is to broaden the teaching content of Outline, attract college students' interest in learning with innovative and creative economic historical materials, make contemporary college students deeply understand the deep-seated spirit of economic construction in revolutionary base areas, and cultivate students' innovation and scientific spirit.

【关键词】革命根据地; 经济建设; 教学改革

【Keywords 】revolutionary base areas; economic construction; teaching reform 【DOI】10.36012/sde.v1i3.474

\section{1 引言}

将革命根据地经济建设精神融入《纲要》课程, 首先在课 堂上能够丰富《纲要》课程的教学内容, 帮助大学生树立正确 的核心价值观。其次在课外能够提高大学生的兴趣和实践能 力, 能够使大学生对革命者们进行多维度、立体的认识, 学习 革命领袖的革命热情和专业精神。

\section{2 理论依据}

学术界大多关注红色文化资源和中国共产党舍生取义为 革命流血牺牲。《中国近现代史纲要》(简称《纲要》) 作为一门 从历史的角度对大学生进行思想政治教育的课程, 承担着教 育当代大学生树立正确社会价值观的任务, 而根据地经济方 面的历史故事对学生有着强大的感召力 ${ }^{[1]}$ 。比如, 方志敏在狱 中坚贞不屈的事迹耳熟能详, 但是, 大学生未必都知道这位革 命家在根据地的经济建设方面呈现出的是一位具有经济领域 专业能力的领导者和实干家。方志敏领导赣东北革命根据地 的经济建设留下了关于造币铸币的宝贵经验，财政上余留下 来的资产还可以支持其他的革命根据地。在新民主主义时期, 革命根据地的经济建设中涌现出大量的类似于方志敏这样的 事迹, 可以作为非常生动直观的教学案例, 可以成为丰富《纲 要》课教学实践环节的有效手段之一,让学生认识到一个优秀 的人是可以具备多方面的能力的, 可以引导学生多方面、多维
度构建自己的专业结构, 不局限于某一专业 ${ }^{[2]}$ 。在大革命和土 地革命时期, 有 10 多个大的革命根据地存有丰富的相关史料 和红色文化资源, 可以提供给学生进行实地考察和调研活动, 提升他们的实践能力。因此,有必要把社会主义在革命时期根 据地经济建设的精神融入课程教学中, 融入第五、第六和第七 章之中, 积极进行教学改革, 以整合教学内容, 凸显深化改革 的必要性。

\section{3 国内外研究现状分析}

有关革命根据地的教育价值, 学术界和教育界多从红色 文化资源融人思想政治课的角度进行研究 ${ }^{[3]}$ 。红色文化资源这 一概念是由彭央华和项波 (2003) 首次提出来的, 不过陈始发 等(2014)指出学术界对其定义难以统一。周宿峰(2014)认为 它的内涵应该是由新民主主义革命时期的革命理论、革命实 践、革命经验和革命精神组成, 是无比珍贵的精神财富。这一 观点较为 2 全面, 值得借鉴。精神上的传承性, 是新时代大学 生关切的重点。刘琨(2015)、金民卿(2015)、丁慧民等(2017)、 田轶( 2018 )等论述了革命精神的时代性及其激励作用。郭瑞 敏和王戎(2010)、李成生(2012)、张玉祥(2015)、马霞(2016)、 高伟(2018)和周倩倩(2018)等论及地方红色文化资源融人 《纲要》课程教学的重要性和必须性。宗河( 2014 )从总的方面 论述人们应该把优秀的传统文化融入课程体系。计裕人 (2015) 认为要在《纲要》课程体系中融入历史资源, 这样能够 
教育理论与研究 Educational Theory and Research

大幅度地提高学生的积极性和探索的主动性, 教育教学效果 显著增强。贾邚娜和于嘉安( 2016)认为将地方的历史文化资 源融人思想政治理论课，对于强化思想政治理论课，尤其是 《纲要》课的实际效果具有重要的作用。革命根据地就属于这 种地方历史文化资源。这是物化形态的文化资源和精神文化 资源 ${ }^{[4]}$, 对于培养学生的爱国主义精神,引导他们传承优良传 统、弘扬优良作风, 不断增强使命感和责任感, 保持崇德向善 的良好风尚具有重要的作用 ${ }^{[5]}$ 。庄秋菊和彭贵珍(2016)就中 国江西的红色文化资源如何融人《纲要》课程进行了研究, 从 课堂上的以案例、图片和视频的形式促进理论的教学探讨,到 课外的实践活动感受现场提出了措施, 较为具体。关于革命根 据地这种红色文化资源的经济价值, 研究者皆是从旅游带来 的经济增长的角度进行研究, 如石功鹏 (2010)、魏本权 (2011)、渠长根(2017)等。但是未有从革命根据地经济建设成 就展现创新创造精神角度的研究成果 ${ }^{[6]}$ 。

\section{4 具体措施和预期效果}

这种教学内容方面的改进是基于广西师范大学多年来思 想政治理论课研究性学习与实践教学改革的实践成果 [7], 着眼 于提升思想政治理论课教学质量, 增强大学生学习思政课的 满足感和获得感需要, 提高大学生课堂学习的兴趣和参与率, 拓宽实践教学中关于历史文化资源的视角, 解决以往《纲要》 课程教学都是以历史史实展现为主、实践教学以参观历史事 迹为主的模式 ${ }^{[8]}$ 。在课堂上, 结合《纲要》课第四章的第三节 “中国革命的新局面”、第五章的第一节“对革命新道路的艰苦 探索”、第二节“中国革命在探索中曲折前进”, 第六章的第四 节“中国共产党成为抗日战争的中流砥柱” 以及第七章的第二 节“土地改革与农民的广泛发动”等的内容, 加上精心制作的 相关革命根据地的案例资料, 依次加入赣东北革命根据地、中 央革命根据地、闽浙赣革命根据地、鄂豫皖革命根据地、东北 解放区、山东解放区等关于经济建设的相关创造性的实践成 果案例, 以 PPT 或者视频的形式展现给大学生学习 ${ }^{[9]}$ 。同时, 在课外为期一个月的实践教学期间, 组织学生去革命根据地 开展 “学习革命根据地经济建设创新精神” 为主题的实践活 动, 能够提高大学生的兴趣和实践能力 ${ }^{[10]}$, 使大学生对革命者 们进行多维度、立体的认识, 学习他们的革命热情和专业精 神, 从而激发个体的激情, 去建构自己的多面手学习目标 ${ }^{[11]}$ 。 教师要形成关于《纲要》课程相应的革命根据地经济建设创新 创造精神的课上案例教学文档, 集结成册, 分发给学生使用, 进一步推动相关理论研究, 公开发表形成的相关教改论文, 探 讨教学改革 ${ }^{[12]}$ 。

\section{5 结语}

拓宽《纲要》课程教学课上的教学内容, 以具有创新性创 造性的经济类史料, 来吸引大学生的学习兴趣, 培育大学生踏 踏实实、一丝不苟、严谨细致、不畏艰难的“工匠精神”。革命根 据地在进行经济建设的时候, 建造铸币厂、造币厂生产纸币 ${ }^{[13]}$ 。 这其中的技术环节是克服了各种艰难困苦的。比如, 大革命时 期赣东北革命根据地在造币和铸币上的耐心摸索、反复实践、 一丝不荷的精神, 使受教的大学生认识到革命都余了流血牺 牲之外, 还有着可以运用到现在大学生学习和生活中的专业 精神 ${ }^{[14]}$ 。组织学生去革命根据地开展 “学习革命根据地经济建 设创新精神” 为主题的实践活动, 体现了中国共产党人在新民 主主义革命时期崇高的理想信念、道德情操以及高度的专业 建构能力。应把革命根据地经济建设的创新创造史料作为案 例, 使大学生认识到中国共产党在经济建设上有着强大的创 新创造的传统, 坚定他们对中国共产党的忠诚度。

\section{参考文献}

[1]李康平.红色资源研究与高校思想政治教育 $[J]$.高校理论战线, 2007(6):34.

[2]钟秀利,杨艳春, 罗春洪.试析红色文化的政治价值一执政文 化的视角[J].求实,2007(11):31-33.

[3]陈世润,李根寿. 论红色文化教育的社会价值 [J].思想政治教育 研究,2009,25(4):15-17.

[4]刘强安.信息时代会计信息系统的构建[J].四川会计,2003(2): $40-41$.

[5]李承霞. 运用红色资源开展党性党风党纪教育[J].中外企业家, 2013(34):248-251.

[6]毕于建,杨金莲.利用红色文化资源开展高校《纲要》课实践教 学的探索[J].中国成人教育,2013(19):156-158.

[7]刘强安,覃志刚.美国不动产税制及与地方财政关系的经验与 借鉴[J].管理现代化,2013(4):96-98.

[8]陈始发, 李立娥.红色文化资源在高校思想政治理论课教学中 运用的思考[J].思想理论教育导刊,2014(11):70-73.

[9]冯晶桦.革命老区校园红色文化建设的创新实践 [J].基础教育 研究,2015(21):17-18.

[10]魏俊.明代白银货币化进程及其启示 $[J]$. 求索,2016(1):167-172.

[11]刘强安.试论会计信息的双重作用[J].财会月刊,2005(11):8-9.

[12]陈丽斌.红色文化自觉与大学生社会主义核心价值观培育研 究[J].鄂州大学:学报,2019,26(3):20-23.

[13]魏俊.广州、粤海关与广州十三行[J].兰台世界,2016(2):96-99.

[14]龙涌澜.红色文化融入高校教育扶贫工作探究 [J].学校党建 与思想教育,2019(14):80-81. 